Binghamton University

The Open Repository @ Binghamton (The ORB)

Winter 2016

\title{
Advancing Global Cultural Competencies: International Service Learning Within NASPAA Member Programs
}

\author{
Susan Appe \\ Binghamton University--SUNY, sappe@binghamton.edu \\ Nadia Rubaii \\ Binghamton University--SUNY, nadia.rubaii@binghamton.edu \\ Kerry Cook Stamp \\ Binghamton University--SUNY, kstamp@binghamton.edu
}

Follow this and additional works at: https://orb.binghamton.edu/public_admin_fac

Part of the Public Administration Commons

\section{Recommended Citation}

Appe, S., Rubaii, N., \& Stamp, K. (2016). Advancing global cultural competencies: International service learning within NASPAA member programs. Journal of Public Affairs Education, 22(2), 67-90.

This Article is brought to you for free and open access by the Public Administration at The Open Repository @ Binghamton (The ORB). It has been accepted for inclusion in Public Administration Faculty Scholarship by an authorized administrator of The Open Repository @ Binghamton (The ORB). For more information, please contact ORB@binghamton.edu. 


\title{
Advancing Global Cultural Competencies: International Service Learning Within NASPAA Member Programs
}

\author{
Susan Appe, Nadia Rubaii, and Kerry Stamp \\ Binghamton University, State University of New York
}

\begin{abstract}
This article posits international service learning (ISL) as a pedagogy that supports internationalization in the field of public affairs and one known to advance global cultural competency in other professions. We present a baseline study of the extent to which ISL is being made available to master's students in NASPAA member programs, and the extent to which existing programs are responding to key challenges of ethics and assessment. The exploratory analysis shows a lack of clear understanding of ISL in professional public affairs education and very few ISL programs being offered in the field. Among the programs that do exist, there is a commitment to ethical practices and to creative approaches to overcoming challenges. However, these programs have yet to apply systematic assessment, particularly in evaluating their contributions to global cultural competencies. We conclude with a series of recommendations targeted to public affairs faculty, program directors, and NASPAA.
\end{abstract}

\section{KEYWORDS}

International service learning, global cultural competencies, professional education, exploratory research

Universities are charged with creating active, engaged citizens, and given the pressures of globalization, this translates into producing active, engaged global citizens. Arguably, this charge is particularly relevant for education in the field of professional public affairs. To be effective protectors of the public interest, public administrators must be "prepared to advocate for diverse populations" (White, 2004, p. 114), and if public service professionals lack cultural competence, negative consequences may result for their particular clients as well as for the general public (Rice, 2007).

Cultural competencies have been described in a variety of ways in the public affairs field, all of which emphasize that these competencies represent more than a simple awareness or tolerance of diversity and must advance to the application of knowledge and skills (see, for example, Carrizales, 2010; Lewis, Lewis, \& Williams, 2012; Norman-Major, 2011; Rice \& Matthews, 2012; Rubaii \& Calarusse, 2012; Wyatt-Nichol, Brown, \& Haynes, 2011). In a world characterized by increasing global interconnectedness, the concepts of diversity and cultural competence extend beyond the boundaries of one's individual organization, community, or nation.

The globally interdependent nature of public governance is reflected in the Network of Schools 
of Public Policy, Affairs, and Administration's (NASPAA's) newer standards, adopted in 2009. All accredited programs must demonstrate that their graduates have the ability "to communicate and interact productively with a diverse and changing workforce and citizenry," "to articulate and apply a public service perspective," and "to lead and manage in public governance" (Network of Schools of Public Policy, Affairs, and Administration [NASPAA], 2014, p. 7). These standards imply yet do not explicitly mandate global cultural competence. Regardless of whether the standards require global cultural competency or not, the profession demands it (Norman-Major \& Gooden, 2012). As Ryan (2010) effectively articulates, "future [public] administrators benefit greatly from non-U.S. experience... [and therefore]...we need to get them off campus and out of the country" to develop their intercultural competencies (p. 308).

Within this context, many universities are placing greater emphasis on internationalization in its many forms. One way in which internationalization manifests is through international opportunities for students, specifically study abroad programs, including those housed within and administered by specific degree programs. Among NASPAA member programs, in-house study abroad experiences take one of four forms: direct enrollment semester or academic-year programs, dual-degree programs, individualized projects, and short-term programs (Rubaii, Appe, \& Stamp, 2015). The fourth category includes international service learning (ISL) programs.

In this article we posit ISL as a pedagogy that supports the process of internationalization and that has been demonstrated to advance global cultural competency in other professions. We then present a baseline study of the extent to which ISL is being made available to Master of Public Affairs/Master of Public Policy (MPA/MPP) students in NASPAA member programs, as well as the extent to which existing ISL programs are responding to key challenges of ethics and assessment. We conclude with a series of recommendations, based upon our findings, that are targeted to public affairs faculty, program directors, and NASPAA.

\section{INTERNATIONAL SERVICE LEARNING}

As universities seek to prepare citizens to be effectively active in their communities, service learning in particular has become an approach to complement higher education objectives (D'Agostino, 2008; Stout, 2013; Thomson, Smith-Tolken, Naidoo, \& Bringle, 2011). This pedagogy has gained attention across several fields and is quite familiar, at the domestic level, in public affairs education. Service learning is distinct from simply volunteering (on the part of individuals) as well as from community engagement projects coordinated by university faculty or staff. It is a type of experiential learning that engages students in community activities as an integrated aspect of a course. In contrast to practice-based education (e.g., residencies, internships, fieldwork, co-op programs), where students are developing professional skills, service-learning classes involve students in community activities that are linked to a course's specific learning objectives (Kiltz \& Ball, 2010; Lambright, 2008; Lambright \& Lu, 2009; Romack, 2003).

ISL, in particular, has become increasingly popular across several fields (Crabtree, 2008; Moore McBride, Lough, \& Sherraden, 2012). ISL can be defined as the following:

a structured academic experience in another country in which students (a) participate in organized service activity that addresses identified community needs; (b) learn from direct interaction and cross-cultural dialogue with others; and (c) reflect on the experience in such a way as to gain further understanding of course content, a deeper understanding of the global and intercultural issues, a broader appreciation of the host country and the discipline, and an enhanced sense of their own responsibilities as citizens, locally and globally. (Bringle \& Hatcher, 2011, p. 19) 
The literature on internationalization in public affairs education is quite limited (Rubaii et al., 2015), and among the sources that do exist (i.e., Devereux \& Dunning, 2001; Murphy \& Meyer, 2012; Ryan, 2010), none give attention to ISL or mention it as a possible tool to rouse public affairs schools to think and act more globally. Despite this gap, we can assert with reasonable confidence that ISL programming can produce learning outcomes that support all five core competencies of NASPAA (Stout, 2013). Specifically, ISL can center on those competencies related to leading and managing in public governance, applying a public service perspective, and communicating and interacting productively with a diverse and changing workforce and citizenry. We are able to make such assertions because, although the literature about ISL specifically in public affairs education is sparse, there is a rich and growing use and documentation of the pedagogy in other professional fields. In this literature, the potential of ISL to promote global cultural competencies is clearly established, as are some of ISL's potential challenges or pitfalls.

\section{The Potential for Promoting Global Cultural Competence}

The fields of business, engineering, nursing, and social work all have documented evidence of how ISL programs support the particular values, competency needs, and learning outcomes of their respective professions. Generally, ISL allows for an immersive international experience, which is widely recognized as an effective strategy to help students recognize their biases, develop appreciation for different cultures and contexts, and build skills in effective intercultural communication (Cheney, 2001; Crowne, 2008; Deardorff, 2006) as well as to help produce global citizens (Dolby 2007; Douglas \& Jones-Rikkers, 2001; Horn \& Fry, 2012).

Among business educators there is a growing acceptance that graduates need cross-cultural competency to be effective managers. Business programs and educators have turned to ISL to provide students with an experience that will afford them "broader work-related compe- tencies, such as cross-functional thinking, teamwork, interpersonal interaction, communication, and multicultural sensitivity" (Metcalf, 2010, p. 155). Business schools recognize the need to create and educate global leaders and have begun innovative programs with nongovernmental organizations (NGOs), social entrepreneurs, and international organizations. For example, business schools and PricewaterhouseCoopers have partnered in the wellknown Project Ulysses, which seeks to "help managers develop the knowledge, skills, and mind-set that will enable them to successfully support a company's global sustainability and corporate social responsibility efforts" (Pless, Maak, \& Stauhl, 2011, p. 873).

In the context of engineering, Borg and Zitomer (2008) discuss how ISL has been used to address the need for fresh water in Guatemala. They describe how they designated two teams of students, one for design and the other for implementation, to create on-site solarpowered water pumping for an orphanage. In preparation for the ISL experience, students were given readings, discussion topics, and journaling assignments to help them gain a better understanding of the cultural and economic conditions and historical realities of Guatemala.

Weekly meetings and assignments while preparing for the international portion of an ISL program were identified as important for engineering ISL programs (Borg \& Zitomer 2008; Friesel, 2010). In addition to the hard skills of engineering, the authors comment that "discussion periods with readings followed by reflection and group discussion...reinforced the experiential education process through a cycle of action and reflection" (Borg \& Zitomer, 2008 , p. 181). The discussion questions were based around the concept of a global community; on Day 1 of the ISL experience, students were asked: "What role does the practice of engineering play in a society or even globally?" Open-ended questions allowed students to become more self-aware of their actions and impact on the larger society (Borg \& Zitomer, 2008). 
ISL is recognized as a valuable experiential learning tool in the health care professions as well, with specific applications for students of nursing, medicine, and physical therapy. Because of the rapid rate of globalization, medical educators, like business school and engineering faculty, are calling for a dynamic cross-cultural curriculum (Pechak \& Thompson, 2009). One innovative program brings together medical profession students from three universities, including nurse practitioner candidates, nursing candidates, and medical students, to complete an ISL program in Honduras (Green, Comer, Elliot, \& Neubrander, 2011, p. 302). The program was created out of students' desire to perform community service and to interact and provide medical care in a culture different from their own. Program elements include a mobile medical unit that goes to marginal areas of Honduras. Post-trip interviews with students illustrated that the ISL experience was successful in developing four student learning objectives: "stepping outside of my world," "connecting with culturally different people," "awe of community," and "learning innovation" (Green et al., 2011, p. 302).

Social work educators also use ISL to challenge and develop competencies among their students (Gammonley, Rotabi, \& Gamble, 2007; Phillips, 2011). "In a country that is radically different from our own in terms of resources and perspectives, students are challenged more directly to explore the 'meaning, context, power, history, and possibility' of social work practice" (Gammonley et al., 2007, p. 116). An ISL experience encourages students to challenge and understand the ethical principles boasted by the National Association of Social Workers. For example, one of the principles relates to social workers challenging social injustices. Students in a social work program, whether at the bachelor's or master's level, will experience issues related to access to basic necessities, such as food, water, and medical care, when engaged in an ISL experience (Gammonley et al., 2007, p. 124). An ISL experience also allows students to be more aware of the resources available and to understand how concepts and theories of social work have been framed by professionals in developing countries (Gammonley et al., 2007, p. 117).

The empirical studies referenced above illustrate that ISL has been used to promote cultural competencies specific to each profession. It prepares business students for the world of global competition (Metcalf, 2010; Harris, Belanger, Loch, Murray, \& Urbaczewski, 2011; Pless et al., 2011), helps engineering students prepare for project management outside their home country (Borg \& Zitomer, 2008; Friesel, 2010), lets medical and nursing students practice culturally competent health care (Pechak \& Thompson, 2009), and provides a means for social work students to engage in globally sensitive studies of poverty, disparities, and injustice (Gammonley et al., 2007). Given the successes documented in these sister professions, there is every reason to believe that ISL can advance similar profession-specific cultural competencies within public affairs.

\section{The Danger of Perpetuating Stereotypes and Dependencies}

ISL is often presented as if it is inherently good and provides benefits to both the students engaged in the service and the communities they serve. However, several studies spanning multiple academic disciplines have highlighted the ethical and practical challenges involved in designing and implementing ISL programs (Baker-Boosamra, Guevara, \& Balfour, 2006; Ethics of International Engagement and Service-Learning Project, 2011; Grusky, 2000; Schroeder, Wood, Galiardi, \& Koehn, 2009). If not designed and implemented properly, ISL has the potential to reinforce stereotypes and power differentials across nations and peoples.

In particular, the difficulties of developing on-site partnerships and engaging stakeholders in meaningful participation in ISL program design have been repeatedly observed (Crabtree, 2008; Littlepage, Gazley, \& Bennet, 2012; Moore McBride, Brav, Menon, \& Sherraden, 2006; Wodicka, Swartz, \& Peaslee, 2012). Where community perspectives are not taken into account, ISL programs can be harmful to communities, effectively objectifying those 
served and perpetuating dependencies (BakerBoosamra et al., 2006). The consequences of not properly collaborating with partner organizations and communities can be destructive: "Without community partners defining their own objectives for participation in servicelearning programs, the community becomes little more than a laboratory for the use of privileged students rather than being a true partner in learning" (Baker-Boosamra et al., 2006, p. 485).

Questions to pose include, for example: What are the economic impacts of study abroad on the local community? How does student consumption impact communities? Are students prepared to understand the local community? (Schroeder et al., 2009). Many faculty and staff-some very experienced in leading international programs - do not fully consider the possible negative consequences of their programs on local communities (Crabtree, 2008; Schroeder et al., 2009). Crabtree (2008), who has significant experience leading ISL, proposes that educators think critically about ISL and improve ISL design and practice to truly examine values of global significance.

To address the ethical challenges of ISL, the value of solidarity has been emphasized in ISL, in Spanish-speaking countries in particular (Baker-Boosamra et al., 2006). Baker-Boosamra et al. (2006) use their ISL program in El Salvador to illustrate "three interrelated and overlapping notions" of solidarity: reciprocity, mutuality, and power (p. 484). Reciprocity is the notion that university and community stakeholders are partners in the educational experience and that both groups realize the benefits of service. Mutuality allows for the creation of a common vision among stakeholders. Mutuality centers on balancing academic and university interests (such as student learning objectives and faculty interests and research) with desired outcomes defined by the communities served. The third concept, which Baker-Boosamra et al. (2006) label power, acknowledges existing power differentials and asserts that community members need to be validated and not merely helped by the ISL experience.

\section{The Importance of Assessment}

ISL is fundamentally different from traditional classroom instruction in both its delivery and its goals. As such, it warrants tailored assessment instruments and processes (see Tonkin, 2011). It is one thing to assert that ISL advances global cultural competency, but such assertions must be supported by empirical studies in which such competencies are defined and measured, and in which any changes observed can be attributed to the ISL experience. As noted earlier, several professional disciplines have defined global cultural competencies in terms specific to the 21 st-century demands of their professions, and these disciplines have engaged in systematic collection and analysis of information to document the effectiveness of ISL in expanding students' global perspectives and enhancing their cultural competencies.

Another important aspect of designing ethical ISL programs that advance cultural competencies and build solidarity is that program assessment must draw upon input from all stakeholders (Longo \& Saltmarsh, 2011). That is, program effectiveness must be gauged not simply by faculty satisfaction or even student competencies, but also via feedback from service partners outside the home country and, ideally, from the communities they serve. The values of solidarity, global citizenship, and cultural competence therefore extend to program design, implementation, and assessment. Linking back to the earlier assertions about ISL's potential to contribute to global cultural competencies, it is also critical to define, measure, and assess such competencies within the ISL context.

\section{RESEARCH METHODS}

Because there is little literature on the internationalization of public affairs and even less on ISL in this field, this research is exploratory. In the absence of published literature on ISL specific to public affairs, our first task was to gather some baseline data. We use that data to assess the extent to which existing ISL offerings within public affairs programs attend to the challenges presented in the broader literature, and we use our findings as the basis for 
recommendations for the field. Our research is guided by three research questions:

1. To what extent are public affairs programs providing students with ISL opportunities?

2. To what extent and in what ways are existing ISL programs in public affairs addressing the ethical and practical challenges identified in the literature?

3. To what extent and in what ways are existing ISL programs in public affairs engaging in systematic assessment of ISL as a tool to advance students' cultural competencies?

We collected data using a sequential mixed methods approach (Creswell, 2003). First we collected quantitative data through a survey, which was followed by qualitative data collection through interviews. The two-stage process involved an electronic survey administered during October 2013, and follow-up interviews conducted via phone or Skype in February and March of 2014. The data collection combined closed-ended questions on the survey and openended questions during the semi-structured interviews. Using the membership list maintained by NASPAA, we sent e-mails to 275 principal program representatives ${ }^{1}$ with a brief explanation of the research purpose and a link to a seven-question survey instrument (see Appendix A for the survey instrument). We received completed surveys from 140 institutions, representing a $51 \%$ response rate.

Although almost all of the universities offered study abroad opportunities for their students, the majority of these opportunities were targeted to undergraduate students and not designed explicitly for professional graduate education nor for public affairs. As such, our focus was on study abroad opportunities administered at least in part by the university's MPA/MPP program, which we labeled "in-house" study abroad. In the survey, public affairs programs that reported offering in-house study abroad opportunities were asked to provide names and contact information for the individual or individuals with greatest knowledge of and responsibility for these programs.

Individuals designated by the survey respondent were contacted by one of the three researchers, initially via e-mail during the week of January 27-31, 2014, with a request to schedule a phone or Skype interview during the period of February 17-28, 2014. Follow-up e-mails were sent in late February and early March, and the last of the interviews was conducted on March 18, 2014. Ultimately, we conducted interviews of 20 to 45 minutes in length with 52 individuals from 44 NASPAA member programs. Questions about study abroad program design were asked of all 52 interviewees; further questions were asked of those whose programming included ISL opportunities (see Appendix B for the interview protocol). The characteristics of study abroad programs within NASPAA schools and further recommendations are presented in a separate paper (Rubaii et al., 2015). Here we focus our attention only on the small number of interviewees who indicated the availability of in-house ISL programs for their students.

Among the 140 survey respondents, 91 programs (65\%) provided some type of study abroad opportunity for their students, and $64 \%$ of those $(n=58)$ indicated that the opportunity was offered in-house. Among the 58 programs that offered in-house study abroad programs, 24 program representatives reported that at least one in-house study abroad program offered an ISL component; 2 reported they were "not sure" about an ISL component, and 1 indicated that the school was developing an ISL opportunity. However, during the qualitative interviews, the total number of programs offering in-house ISL opportunities was refined downward to only 7 NASPAA member programs (see discussion of results under Finding 1 below). While the number of interviewees and discrete programs is thus small, which significantly limits our ability to generalize results, it represents the population of respondents currently offering ISL opportunities and thus warrants further study. 
The qualitative interviews explored the research topic using largely open-ended questions and provided an opportunity for interviewees to elaborate on their study abroad programs in a semi-structured format. Each of the authors conducted two initial interviews as a pretest with the interview protocol. The protocol was then revised to refine question phrasing and to add a final open-ended summary question about lessons learned. Each researcher transcribed her own notes, and then one researcher's graduate assistant aggregated and compiled the transcribed notes in two forms - one organized by question, and the other by university. The two faculty researchers analyzed the qualitative interview data. The faculty researchers thematically coded responses to reflect the richness and range of responses. Themes were evaluated by all three authors and independently applied to the data to provide a measure of interrater reliability. Qualitative analysis served to gain meaning from the data and produce a baseline to empirical knowledge about ISL programs in public affairs education (Corbin \& Strauss, 2008).

\section{FINDINGS}

From this exploratory study, we identified five principal findings. The first two findings relate to the extent to which public affairs programs are providing students with ISL opportunities. The third and fourth findings address the ways and the extent to which existing ISL programs in public affairs are addressing the ethical and practical challenges identified in the literature. The final finding focuses on the ways and the extent to which existing ISL programs in public affairs are engaging in systematic assessment of ISL as a tool to advance students' cultural competencies. Each finding is presented in turn below. The findings together then serve as the basis for the subsequent discussion of implications and recommendations.

\section{Finding 1:}

\section{Lack of a Clear Understanding of ISL}

The first finding, which was revealed by the sequential research process of surveys followed by interviews, is that there is a lack of clarity among public affairs faculty about ISL itself. At the survey stage, we inquired about ISL opportunities, but did not define the term (see Appendix A: Survey Instrument, Question 6). As stated earlier, in response to the survey, 24 program representatives reported that they offered at least one in-house study abroad program with an ISL component, while 2 other respondents indicated they were unsure and 1 indicated that the school was developing an ISL program.

At the interview stage, we were able to probe deeper into program offerings and design, and we found the number of ISL programs to be considerably less than initially reported during the survey. During the interviews, we provided respondents with the following definition of ISL:

For our purposes, service learning is a type of experiential learning that engages students in volunteer activities within a community as an integrated aspect of a course. In contrast to practice-based education (such as internships or fieldwork), where students are developing professional skills, service-learning classes involve students in volunteer activities that are linked to specific learning objectives of the course. International service learning is an organized excursion taken by students in which students volunteer with local organizations to service the community where they are staying, engage in a cultural exchange, and learn about a daily reality very different from their own. International service learning involves intentional and continuous reflection before, during, and after the service experience.

Using this definition, only 7 public affairs programs-representing only $5 \%$ of the 140 programs originally surveyed and less than $30 \%$ of the 24 that had indicated that they offered ISL-were determined to have at least one in-house ISL program. This suggests that within the field of public affairs, the term service learning is being used more widely and with a looser definition that does not conform to the standards and criteria accepted in the literature. 
TABLE 1.

Profile of NASPAA Member Schools With ISL Programs $(N=7)$

\begin{tabular}{|c|c|}
\hline Type of university & $\begin{array}{l}\text { Public: } 5 \\
\text { Private: } 2\end{array}$ \\
\hline Location of university & $\begin{array}{l}\text { U.S. Northeast: } 2 \\
\text { U.S. Midwest: } 2 \\
\text { U.S. West Coast: } 2 \\
\text { U.S. Southwest: } 1\end{array}$ \\
\hline Degree(s) offered & $\begin{array}{l}\text { MPA: } 7 \\
\text { MPP: } 0 \\
\text { MPAff: } 0 \\
\text { Other public affairs master's degrees: } 2 \\
\text { Baccalaureate: } 1 \\
\text { Doctorate: } 6\end{array}$ \\
\hline NASPAA accreditation & $\begin{array}{l}\text { Accredited: } 6 \\
\text { Not accredited: } 1\end{array}$ \\
\hline Mission & $\begin{array}{l}\text { International reference in MPA mission: } 4 \\
\text { International reference in school mission: } 6 \\
\text { No international reference in mission: } 1\end{array}$ \\
\hline Location of ISL program(s) & $\begin{array}{l}\text { Latin America: } 5 \\
\text { Africa: } 3 \\
\text { Asia: } 2 \\
\text { Canada: } 2\end{array}$ \\
\hline Number of ISL program(s) & $\begin{array}{l}\text { One: } 2 \\
\text { Two: } 2 \\
\text { Three to five: } 2 \\
\text { Six or more: } 1\end{array}$ \\
\hline Status of ISL program(s) & $\begin{array}{l}\text { Mandatory: } 0 \\
\text { Recommended: } 4 \\
\text { Optional: } 3\end{array}$ \\
\hline
\end{tabular}

Notes. ISL = international student learning. MPA = Master of Public Administration. MPAff = Master of Public Affairs. MPP = Master of Public Policy. NASPAA = Network of Schools of Public Policy, Affairs, and Administration . 


\section{Finding 2: Few Opportunities for ISL}

Given the push for internationalization at universities, the field of public affairs' growing interest in building cultural competencies, and the documented evidence of ISL effectiveness in other professions, we were surprised by the small number of programs found to be truly engaging in ISL. Despite being small in number, the public affairs programs that do offer ISL warrant closer examination. The seven NASPAA member programs that offer ISL have over 20 ISL offerings and can provide a baseline understanding of the current state of activities as well as inform decisions made by other public affairs programs interested in developing ISL opportunities for their students. We interviewed at least one person from each of the seven programs and in two cases we were able to interview three people involved with different ISL programs. Our findings are therefore based on a total of 11 interviewees from the seven programs that provide in-house study abroad ISL programs.

While the total number of NASPAA member programs offering their students ISL opportunities is strikingly small, the characteristics of the programs that provide these opportunities suggest that ISL is not limited to a particular type or size of school or program (see Table 1). ISL opportunities are found in both public and private universities and are not exclusive to NASPAA-accredited programs. As with recent research findings related to study abroad programs more generally (Rubaii et al., 2015), the creation of ISL opportunities seems to be largely motivated by individual faculty interest. Among the seven NASPAA member schools offering ISL opportunities to their students, most of the programs take place in developing countries in Latin America (five schools); Africa (three schools); and Asia (two schools). Two of the seven public affairs programs have ISL opportunities in Canada.

\section{Finding 3: A Demonstrated Commitment to Ethical Practices}

Among the small number of ISL programs within public affairs, we found an impressively strong commitment to addressing the ethical challenges of ISL, through building and maintaining partnerships, incorporating language learning in the ISL program, explicitly addressing ethical practice during the academic portion of the course, and using a process of systematic reflection before, during, and after the ISL experience. The discussion of this finding that follows is presented in terms of four promising areas of practice.

\section{Finding 3A: Building and Maintaining Relation-}

ships. As outlined in the literature review, perhaps one of the most important components to ISL programming is building responsible partnerships. When asked specifically about ethical considerations, respondents for all seven programs discussed the importance of building and maintaining relationships with partners. They observed that strong on-site partnerships are paramount to ethical ISL, and all seven public affairs programs had worked with consistent partners over time.

Across the sample, partners varied; they included international NGOs, universities, local nonprofit organizations, language schools, and on-site government agencies. There was no pattern to the type of partner based on the type of public affairs program or university. The type of partnership was specific to each ISL program and varied across individual ISL programs even within a single public affairs program. Despite variation in the types of partnerships, all seven public affairs programs had ISL opportunities that repeated on an annual, biennial, or rotating basis, and all programs worked with the same partners continually. One example: at a private university in the U.S. Northeast that offered seven ISL programs out of its public affairs program (the most opportunities in one program in our sample), a faculty leader said, "Consistency in service partners is critical, because we want to have a long-term impact. That requires trust and ongoing relationships. The work is more effective in this context." The faculty member expanded on this, observing that "collaborations must be done in a respectful manner. 
For sustainability this cannot be ad hoc. To build trust and a sense of partnership, you need the same faculty to return year after year." Faculty leaders at five of the seven public affairs programs with ISL observed that good partnerships and mutual trust are not only ethical and aid sustainability but also provide a higher level of security and safety for the students and faculty.

Some schools engaged in a purposeful strategy to build and maintain true partnerships. For example, one public affairs program at a public university in the Midwest partners with an international NGO for its ISL program in East Africa. The faculty leader we interviewed said that their public affairs program had a strategy when looking for partners for international programming; it wants an organizational partner whose mission and goals are aligned with the public affairs program's mission. The faculty leader had attended a presentation by the international NGO and described it as "brilliantly" aligned with the school's MPA program and its mission.

Finding 3B: Attention to Language and Culture. Many ISL programs take students to countries where English is not the native or dominant language, and language and cultural immersion were explicit goals of many of the ISL programs in the sample. Indeed, when ISL extends to a non-English-speaking country, there exist opportunities for true global learning. ISL has the potential to help students appreciate how language and culture are intrinsically linked.

Faculty leaders observe this learning opportunity and often integrate language into program learning objectives. For example, a 1-month ISL program in East Africa offered by a public university in the Midwest includes an intensive language and culture course for the first week. The expected learning outcome is the ability to introduce oneself in the native language. In addition, culture is very much integrated into the language courses. The faculty leader spiritedly explained that "culture as well as language is important. For example, U.S. students always want to talk about their pets, but this is seen as ridiculous" by the locals. In addition, while on site during the service projects, students "are deliberately spaced and assigned to maximize contact and conversation." Another faculty leader, of an ISL program in Latin America, similarly observes the importance of language to relationship building with partners. The faculty leaders stated that if students did not have some language skills, it "would burden the [partner] organization.”

An ISL program in a Spanish-speaking country in Latin America offered by a public university in the Northeast integrates language classes into the on-site part of the ISL experience. Students' Spanish language skills can range from beginner to native speaker. Students receive formal language instruction tailored to their individual language abilities and interests at an accredited on-site language school. Native Spanish speakers have the opportunity to study the indigenous language of Quechua, which provides additional opportunities for them to more fully experience the cultural exchange and communicate with indigenous communities. In places with languages that are not among the major world languages, in particular,

students see that languages are particularly vulnerable since they are not considered prestigious or valuable enough for engaging in the global dialogue. In a global society, language embodies the intellectual wealth of the people who speak it, and it is used to construct meaning in ways that are natural and relevant to the needs dictated by the local society. (Garcia \& Longo, 2013, p. 119)

In this ISL program, the language and cultural immersion extends beyond the formal classes to include housing with host families as well: Students and faculty live with families during their entire stay in country.

In one case, the university's characteristics largely influence the ISL programming in its public affairs program. The faculty leader at a private university on the West Coast highlighted that the nature of the university's 
internationalized graduate degree programs influenced the design of the ISL programs for MPA students. When asked about language and cultural immersion, this faculty leader noted that all admitted students either are required have studied abroad as undergraduates or are from another country and thus coming to the United States is their study abroad. Additionally, all students in this university's public affairs programs speak both English and at least one other language. The school also has a United Nations-certified interpretation program, so when needed, an interpreter may be taken along during international programming to aid with language barriers.

Finding 3C: Academic Course Content. Several interviewees discussed the integration of academic content into the ISL experience as a means of promoting appreciation for public service values and ethical practice. This focus on academic content was particularly notable among the ISL programs in developing countries in which the coursework centered on community and sustainable development.

One of the ISL programs in East Africa focuses on NGO work in international development, which tends to attract MPA students who are interested in NGO management and international development. Another ISL program, in Latin America, focuses on actors in local development, including local government and local nonprofit organizations, and this focus mirrors the MPA program's specialization offerings. The Latin American program situates local sustainable development practice as interconnected between environmental issues, economic viability, social equity, and cultural identity. MPA students participating in this program can elect to do their final research and reflective papers on the roles of local government or nonprofits in sustainable development, thus this elective can count toward either of the MPA specializations. Another ISL program that travels to Latin America includes academic content related to program evaluation in a course called Evaluation of Development Impact. In this program, the students participate in a multiyear on-site monitoring and evaluation of an environmental cleanup project sponsored by the World Bank and the local government.

Several faculty leaders identified the building of ethical considerations into the coursework as a way to advance learning objectives. Preparation included targeted conversations and ensuring student readiness. Additionally, course content that asks critical questions specific to the pedagogy of ISL can be included in a program so that students understand the implications and advance their understanding of ethics and reciprocity (Longo \& Saltmarsh, 2011), and all 11 interviewees associated with the seven inhouse ISL programs reported this for their programs. For example, one faculty leader identified ethics as part of its three-prong ISL course series, along with the substantive course topic and the language training component.

Faculty leaders of ISL programs purposely engage in ethical conversations. For example, one faculty leader stated, about the coursework of multiple ISL programs, "The course includes an international programs lab, discussions of cultural contexts and how to be respectful, and linking this to the core mission and the values of exchange rather than imposing expertise." Another faculty member, who leads an ISL program to Latin America, listed readings that serve as good launching points to engage students in ethical considerations; readings included Baker-Boosamra et al.'s (2006) work on solidarity in ISL, cited previously; ZemachBersin's (2008) reflection on global citizenship from a student's perspective; Grusky's (2000) piece on the complexities of ISL; and the provocative piece To Hell With Good Intentions by Illich (1968). Additionally, a 2013 documentary looking at the implications of international travel is included in this curriculum. The faculty leader reported that the documentary, Gringo Trails (Vail, 2013), poses critical questions about global travel, the market of tourism, and their effects on cultural identity and sustainable development.

In addition to introducing students to material related to ethical considerations in ISL, one program tries to reframe ISL as "community-based 
learning" to mitigate the ethical issues. The faculty member interviewed asserted that the intention was to recognize that the program's primary goal was student learning, not service:

So when we enter a community...we enter it for the purposes of learning and value the expertise of our community partners... We reframe it as an opportunity to learn [in order to]... avoid the issue of seeing our community partners as people who are in need, instead [of] as assets.

\section{Finding 3D: Planned, Systematic, and Ongoing} Reflection. When asked about lessons learned from leading an ISL experience, one faculty leader from a public university in the Midwest, who leads an ISL program to East Africa, stated that it is "absolutely essential to build in reflection time. The feedback from students is they want more of this." Short-term ISL experiences in particular face challenges because of the time frame; culture shock and reverse culture shock become potential barriers to achieving learning objectives (Crabtree, 2008). Thus, formal preparation and ongoing reflection, before, during, and after the trip, are important and were consistently brought up by interviewees.

One ISL model developed by faculty members at a public university in the Northeast included three half-day course sessions before the trip abroad. The pre-trip sessions included academic rigor through assignments and reflection. While students and faculty were on-site, in a country in Latin America, they participated in regular debriefings and reflection. The faculty leader noted that given the importance of reflection in the literature on ISL, the need for more of it, as part of the program design, should not have come as a surprise during the ISL program's first year running, in 2013. While reflection as a group started during the three half-day class sessions before departure, scheduled time for reflection was not initially put into the on-site itinerary. The faculty leader reported quickly learning on the ground that they needed more group reflection time, needed time set aside for academic seminar sessions, and needed to have these scheduled in advance for subsequent years.
In this program's first year, the faculty leaders were able to improvise and hold reflection sessions during group lunches. In addition, all students were encouraged to meet individually with the two faculty leaders at least once to discuss and reflect on their linking of the academic course material to their experience on the ground. The faculty leader interviewed explained that "the reflection and debriefing discussions greatly enhanced and contributed to [the students'] experience during the program.”

An ISL program in East Africa offered by a public university in the Midwest engages students in several types of reflection. Before leaving for the trip, students write a letter to themselves about their expectations. These letters are returned to them, on the plane returning to the U.S., for an immediate reflection about the experience versus the expectations. In addition, while on site, the faculty leader holds weekly "pub administration" sessions over drinks, where "students have blunt conversations about controversial issues" but in a more informal setting.

In addition to pre-departure and on-site reflection, re-entry reflection and follow-up action plans are identified as important parts of ethical and effective ISL design and practice (Crabtree, 2008). Developing action plans after ISL experiences can be challenging. Students want to apply their shifted perspectives, but confront barriers once home and back into their routines (Crabtree, 2008). One faculty leader from a public university in the Northeast mentioned that the ISL program they lead to Latin America has created a model for continued reflection of the experience once faculty and students return to the United States. Program alumni meet several times the following semester to continue the dialogue about the learning experiences . The program has also held several on-campus activities, such as panel discussions and other presentations, to share the ISL experience with various U.S. audiences as part of its reflection.

Finding 4: Creative Approaches to Challenges Beyond the ethical concerns, the literature documents a number of administrative challenges associated with ISL. Academic and logistical 
pressures consume preparation time and leave little time for faculty and administrators to think about important programmatic design elements (Baker-Boosamra et al., 2006; Perold et al., 2012). Conflicting pressures may arise, as university administrators and even external funders are more likely to focus on student learning outcomes and less likely to consider other critical dimensions, such as partnership and relationship building (Schroeder et al., 2009). Doing ISL well is a great deal of work; it requires faculty who are dedicated, have the support of their institutions, and/or are creative in managing their time and other resources. As one faculty leader, who has led a program to East Africa every other year for several years, put it: "It is impossible to overestimate how much work ISL is. It is exponentially more work than expected."

Given the programmatic design elements outlined above-considering the ethics of ISL, building and maintaining partnerships, including language and cultural immersion, and providing an academically rigorous experience with ongoing reflection-it is not unexpected that the faculty leaders we interviewed recognized the need for institutional buy-in and acknowledged the demanding workload of ISL design, planning, and implementation. We found that they also had developed some creative and effective strategies for addressing these challenges.

Faculty leaders mentioned lack of institutional support specifically as a challenge. For example, one faculty leader, from a West Coast public university, stated: "To be brutally honest about it, [the university] was dragged kicking and screaming into [international programming]. The university has traditionally been [state]focused. But people in the community started to recognized that rapid immigration was having an impact." As the international programs became more popular, particularly study abroad and ISL programs, student tuition and fees were able to cover programmatic costs. The faculty member noted that when less financial resources were needed, the university became more "enthusiastic."
Another faculty leader, also from a public university on the West Coast, encouraged further investment in ISL programming. The faculty member stated:

[ISL is] time intensive, energy intensive... it creates opportunity cost...but having really successful programs starts with investment, and that starts with faculty. Most institutions, American institutions, don't work that way. [We need to find] ways to encourage and nurture the faculty investment [in ISL] over long periods of time.

Several interviewees observed an increase in support for ISL at the department level, particularly for students. One faculty member at a public university in the Midwest stated: "We have a lot of scholarships-through [the school] — the dean provides a large amount of money for students to go abroad." In addition to student financial support, support for faculty development was identified as important.

Another way to capitalize on the time and investment required by faculty and departments is to integrate ISL into research agendas. Faculty work in ISL programming continues to be undervalued in the promotion and tenure review processes of most institutions (Bringle \& Hatcher, 2011). However, 6 of the 11 interviewees across four of the seven public affairs programs with in-house ISL are conducting research related to their ISL leadership experiences. One faculty leader, from a public affairs program in a public university with several ISL programs, coauthored a chapter about the dilemmas of working with binational groups in service projects. Another faculty member, at a public university in the Southwest, conducted her doctoral dissertation on partner perception of service learning and continues with this research. She states: "My research has addressed the approach of working with community instead of for community; not saving the community" (emphasis by the interviewee), and her research has influenced the faculty leader's current ISL program design and implementation. 
This article was motivated by our own experiences with ISL design, planning, and implementation, the questions and challenges we encountered, our desire to understand how other programs were dealing with similar challenges, and the objective of being able to make evidence-based decisions toward improving the quality of our ISL programs.

\section{Finding 5: Lack of Systematic Assessment of ISL}

As presented earlier in this paper, many professional fields have documented the value of ISL in the form of improved cultural competencies. These empirical studies have clearly articulated the specific form of cultural competencies required among students and professionals in their field and have analyzed student competencies both before and after the ISL experience and/or in relation to students who do not partake in such experiences. Public affairs, as a field, has just begun to define global competencies and has yet to engage in a systematic process of assessment of ISL.

As with study abroad programs more generally (Rubaii et al., 2015), the benefits of ISL are gathered almost exclusively through informal processes of observation and anecdotal evidence or through course evaluations designed for conventional courses, and the assessments are almost entirely focused on what the students gain from the experience. For example, one faculty leader at a private university on the West Coast stated that student course evaluations have close-ended and open-ended questions "asking them to assess the experience on three levels: professional, academic, and personal.”

All interviewees were able to recount multiple examples of conversations in which students referred to the ISL experience as a "life-changing experience." In addition, three faculty leaders mentioned using observation to assess program effectiveness and cultural competencies, in order, as one faculty leader explained, to observe if "the program makes an impact on the student."

While all programs included in the study had components of student self-reflection before, during, and after the ISL experience (see Finding 3D presented earlier), only one program engaged in any kind of pre- and post-test assessment. In this case, the West Coast university faculty member, who has led a program in Latin America for dozens of years, explained, "I give students an assignment prior to departure, and after, they rewrite that paper based on what they have learned, so in a sense I have a before/after test."

One program, based at a public university in the Northeast, has begun the process of expanding its assessments to include participants other than students. The faculty member who leads this ISL program to Latin America, which was initiated in 2013, explained that they engage in a purposive multiple-stakeholder evaluation, not only for evaluation purposes but also as a component of building and maintaining partnerships. The faculty leader stated that "systematic evaluations must be conducted to ensure that objectives for the full range of stakeholders are being met." The ISL program administrators and faculty have designed an evaluation methodology to strengthen their ability to understand and include all stakeholder expectations and objectives and thus better meet the programmatic goals.

After the first year of this evaluation, faculty leaders were able to identify areas where partner expectations did not coincide with student and programmatic expectations. The faculty leader reported that they were making program improvements accordingly and stated that evaluations that "elicit feedback from all parties reinforce the equal value on all stakeholders." While noteworthy for its responsiveness to the issues of reciprocity, mutuality, and power (Baker-Boosamra et al., 2006) discussed earlier, this program's assessment process still neither defines nor assesses global cultural competence.

The absence of systematic assessment of ISL, particularly as it relates to advancing cultural competencies, could be portrayed as a criticism of ISL in public affairs. We think it more appropriate to cast this absence as an opportunity to build upon the general progress the 
field is making with respect to competencies. NASPAA accreditation standards have identified the ability "to communicate and interact productively with a diverse and changing workforce and citizenry" as a universal competency (NASPAA, 2014), but have also left to individual programs the task of defining that competency in the context of their own mission. As the profession and programs progress, they will be better positioned to engage in more systematic assessment specific to ISL. Given the extent to which existing ISL programs in NASPAA member programs are fully addressing the ethical challenges of ISL as a pedagogy, we would expect that when studies are conducted, the empirical evidence of effectiveness will be strong and positive.

\section{IMPLICATIONS AND RECOMMENDATIONS}

With only seven public affairs programs reporting that they offer consistent ISL programs, we can safely conclude that ISL in public affairs education is in a nascent stage of development. The findings of this exploratory analysis show that there is a lack of clear understanding of ISL and that very few ISL programs are offered in the field of professional public affairs education. Among the programs that do exist, there is a commitment to ethical practices and creative approaches to overcoming planning and programmatic challenges. However, ISL programs in the field of public affairs have yet to fully apply systematic assessment, particularly with respect to evaluating their contributions to global cultural competencies. Given the small number of schools and the highly individualized nature of ISL programs, our findings are not presented as best practices, but rather as practices that offer the promise of potential value (see, for example, the discussion in Herman \& Renz, 2008, based on the critique of best practices offered by Keechley, Medlin, Longmire, \& MacBride, 1997). So, what do our research findings suggest for faculty and program directors in public affairs and for the discipline as a whole?

Public affairs, both as a discipline and within its ISL programs, needs clarity in basic definitions and measures of global cultural competence. As business educators have defined global cultural competence in the context of global competition in marketing and sales; and as nursing educators have referred to the need to communicate effectively about medical decisions and treatments with individuals of other nationalities, religions, languages, and cultural traditions; so too must public affairs educators define the particular global cultural competencies that their field requires. These conversations are appropriately held among NASPAA leaders and among faculty at individual institutions. In other professions, educators do not refer generically to global cultural competence, but rather place such competencies within the context of specific workplace demands and define them in measurable ways. As public affairs educators, we must do the same.

And as public affairs educators, we need to be doing more. Given the size and scope of NASPAA membership and the importance of preparing current and future generations of public affairs professionals for the global world in which they live and in which they will work, the paucity of ISL opportunities for MPA/MPP students is disconcerting. If global cultural competencies are defined as vital to public affairs, and well-designed ISL programs are demonstrated to contribute to these competencies as they have in other fields, then public affairs programs will need to invest in such programs so that they are more readily available and accessible to MPA/MPP students.

The results of our exploratory study suggest that much can be learned from the promising practices in use among existing public affairs ISL programs. Faculty interested in developing new ISL programs or converting existing shortterm study abroad programs to true ISL experiences can learn from the experiences of our interviewees how to establish, build, and maintain mutually beneficial relationships with partners abroad. They can also examine options for incorporating language learning into ISL so that their programs are not limited to Englishspeaking service locations and yet do not exclude students who speak only English. 
Additionally, the lessons learned about linking ISL experiences to academic course content and incorporating systematic reflection should also inform interested faculty and programs.

Personal connections and faculty interests have been identified as important for the development and maintenance of all types of in-house study abroad programs (Rubaii et al., 2015), and they are even more essential within ISL. Such personal connections and interests serve as the basis for building and maintaining the partnerships which are paramount to ethical, effective, and sustainable ISL programs. For public affairs programs interested in establishing new ISL programs or maintaining or growing existing ISL programs, the time commitment invested by ISL faculty leaders must be recognized. Given the importance of linking research interests with ISL experiences, public affairs programs may find it valuable to incorporate these considerations in their hiring decisions.

It is not clear that global cultural competence acquired through international experience is widely accepted as necessary within public affairs to the extent that it has been embraced in other disciplines. At the broadest level, one of the challenges relates to integrating ISL programming more generally into public affairs curricula and degree programs. As one ISL faculty leader, with dozens of years of experience leading an ISL program to Latin America, stated: "One of the interesting challenges to dealing with these international programs is the extent to which one can envision or incorporate them into broader sets of learning as opposed to treating them in isolation." One way to do this is to give attention to ISL learning outcomes and make them consistent with degree-program learning objectives and parallel with program specializations.

Findings presented in this article highlight ways in which ISL fits well into larger public affairs education learning objectives. We argue that students need to understand and fully appreciate public service values such as ethics, equity, and sustainability in global perspective, and further, need to expand public service values such as solidarity and global citizenship. ISL as a pedagogy, if done well, is particularly well suited to illuminate these values.

As a field, we need to move beyond merely asserting that ISL will advance cultural competence or relying on evidence from other disciplines, to instead gathering and analyzing empirical evidence. Anecdotal evidence, while interesting and informative, does not provide a sufficient base upon which to build ISL programming. Existing programs, and any new programs that are developed, should clearly articulate their stated learning and programmatic outcomes and then measure them. Given the small number of students who generally participate in ISL programs, it may take time to gather sufficient data to facilitate meaningful quantitative analysis; however, data collection should begin sooner rather than later. In the meantime, systematic qualitative data should be collected based on before-and-after assessments, structured reflections, attitudinal surveys, and multi-stakeholder evaluations rather than merely anecdotal examples of success.

\section{CONCLUSION}

This exploratory study of ISL within NASPAA member programs has demonstrated that the public affairs profession is characterized by relatively few ISL program opportunities that meet the widely accepted criteria for ISL established in the literature. On a more positive note, among the small number of ISL programs that do exist, we find that careful attention is being given to key ethical issues of relationships with service partners, language and culture, integration of academic course content, and ongoing reflection. Additionally, our research illustrates that faculty are engaged in creative strategies to overcome resource and time constraints and to garner institutional support; among the most promising practices in this regard is the integration of faculty research with the ISL programming.

Given the relatively recent transition to a competency-based assessment model within 
the NASPAA accreditation standards, perhaps it should not be a surprise that our research also indicates the absence of systematic and tailored assessment of ISL programs in terms of either their impact on community partners or their enhancement of students' global intercultural competencies.

For program administrators and faculty considering the development of new ISL programs, and for those interested in improving the quality of existing programs, we provide advice and recommendations in four areas. First, it is imperative that ISL programs be designed, implemented, and evaluated with attention to ethical practice to ensure that such programs do not reinforce traditional stereotypes and power differentials. There are several promising models and examples within the NASPAA community from which to learn.

Second, the goals of the ISL program should be clearly articulated and ideally should be formed with input from all stakeholders, and not simply based on the ideas of one or a small group of faculty.

Third, if ISL programs are intended to contribute to the development of intercultural competencies on the part of students, such programs must invest time and energy in defining and measuring those competencies both before and after the international experience so that the field of public affairs can develop empirical evidence on par with that of other professional fields. Relying on anecdotal evidence or utilizing course evaluations intended for traditional classroom settings is not sufficient.

Finally, although not directly addressed within the scope of this research, the collective findings suggest the potential for collaborations across NASPAA member schools to increase opportunities for MPA and MPP students without overburdening faculty and program resources. Among the challenges referenced by several of the interviewees was the time required to develop and maintain quality ISL programs. It may not be feasible for all or even a majority of NASPAA member programs to establish ISL opportunities for their students; however, students from universities that lack public affairsbased ISL programs could take advantage of existing programs elsewhere. Linking back to an earlier recommendation, this option would be even more attractive if the existing ISL programs had evidence to document their effectiveness.

In sum, our research shows that despite the proven effectiveness of ISL in other professions, NASPAA member programs are not widely engaged in this pedagogy nor are they assessing existing programs systematically. The programs that do exist, however, are fully attentive and responsive to the ethical challenges of ISL and thus present some promising practices that can inform others. We intend this article to provide a baseline study and an initial guide for public affairs schools. That is, the lessons learned related to ethical and sustainable partnerships, language and culture, academic content, structured reflection, and resources to support the workload demands can inform ISL practice in public affairs and help to foster the pedagogy's integration into the field.

As part of a broader and more comprehensive internationalization effort, ISL can help public affairs educators prepare the next generation of more globally responsible and culturally competent public service professionals. We hope that this article will spur discussions within and among public affairs programs about how to make ISL available to more public affairs students at more universities.

\section{NOTE}

1 The membership list provided by NASPAA in October 2013 included 282 programs; however, only 275 e-mail addresses were functional within SurveyMonkey. Some were rejected because the recipient had previously selected to opt out of SurveyMonkey; others were simply undeliverable. 


\section{REFERENCES}

Baker-Boosamra, M., Guevara, J. A., \& Balfour, D. L. (2006). From service to solidarity: Evaluation and recommendations for international service learning. Journal of Public Affairs Education, 12(4), 479-500.

Borg, J., \& Zitomer, D. (2008). Dual-team model for international service learning in engineering: Remote solar water pumping in Guatemala. Journal of Professional Issues in Engineering Education and Practice, 134(2), 178-185.

Bringle, R. G., \& Hatcher, J. A. (2011). International service learning. In R. G. Bringle, J. A. Hatcher, \& S. G. Jones (Eds.), International service learning: Conceptual frameworks and research (pp. 3-28). Sterling, VA: Stylus.

Carrizales, T. (2010). Exploring cultural competency within the public affairs curriculum. Journal of Public Affairs Education, 16(4), 593-606.

Cheney, R. S. (2001). Intercultural business communication, international students, and experiential learning. Business Communication Quarterly, 64(4), 90-104.

Corbin, J. M., \& Strauss, A. L. (2008). Basics of qualitative research: Techniques and procedures for developing grounded theory. Thousands Oaks, CA: Sage.

Crabtree, R. D. (2008). Theoretical foundations for international service learning. Michigan Journal of Community Service Learning, 15(1), 18-36.

Creswell, J. W. (2003). Research design: Qualitative, quantitative, and mixed methods approaches. Thousands Oaks, CA: Sage.

Crowne, K. A. (2008). What leads to cultural intelligence? Business Horizons, 51(5), 391-399.

D’Agostino, M. J. (2008). Fostering a civically engaged society: The university and service learning. Journal of Public Affairs Education, 14(2), 191-204.

Deardorff, D. K. (2006). Identification and assessment of intercultural competence as a student outcome of internationalization. Journal of Studies in International Education, 10(3) 241-266.
Devereux, E. A., \& Durning, D. (2001). Going global: International activities by U.S. schools of public policy and management to transform public affairs education. Journal of Public Affairs Education, 7(4), 241-260.

Dolby, N. (2007). Reflections on nation: American undergraduates and education abroad. Journal of Studies in International Education, 11(2) 141-156.

Douglas, C., \& Jones-Rikkers, C. G. (2001). Study abroad programs and American student world mindedness: An empirical analysis. Journal of Teaching in International Business, 13(1) 55-66.

Ethics of International Engagement and Service-Learning Project. (2011). Global praxis: Exploring the ethics of engagement abroad. Vancouver, BC: Author. Retrieved from http://ethicsofisl.ubc.ca/.

Friesel,A. (2010). Preparing students for globalizationWorking with international teams with projects. Electronics and Electrical Engineering, 102(6), 111-114. Retrieved from http://www.researchgate. net/publication/267853073_Preparing_Students_ for_Globalization__Working_with_International_ Teams_with_Projects.

Gammonley, D., Rotabi, K. S., \& Gamble, D. N. (2007). Enhancing global understanding with study abroad: Ethically grounded approaches to international learning. Journal of Teaching in Social Work, 27(3), 115-135.

García, N. A., \& Longo, N. V. (2013). Going global: Re-framing service-learning in an interconnected world. Journal of Higher Education Outreach and Engagement, 17(2), 111-135.

Green, S. S., Comer, L., Elliott, L., \& Neubrander, J. (2011). Exploring the value of an international service-learning experience in Honduras. Nursing Education Perspectives, 32(5), 302-307. doi:10.5480/1536-5026-32.5.302

Grusky, S. (2000). International service-learning. American Behavioral Scientist, 43(5), 858.

Harris, A. L., Belanger, F., Loch, K., Murray, M. C., \& Urbaczewski, A. (2011). Study abroad as an education experience: Challenges, realizations, and lessons learned. Communications of the Association for Information Systems, 28, 17-30. 
Herman, R. D., \& Renz, D. O. (2008). Advancing nonprofit organizational effectiveness research and theory: Nine theses. Nonprofit Management \& Leadership, 18(4), 399-414.

Horn, A. S., \& Fry, G. W. (2013). Promoting global citizenship through study abroad. Voluntas, 24(4), 1159-1179.

Illich, I. (1968, April 20). To hell with good intentions. An address to the Conference on InterAmerican Student Projects (CIASP) in Cuernavaca, Mexico.

Keechley, P., Medlin, S., Longmire, L., \& MacBride, S. A. (1997). Benchmarking for best practices in the public sector: Achieving performance breakthrough in federal, state, and local agencies. San Francisco, CA: Jossey-Bass.

Kiltz, L. (2010). Service-learning through colleges and universities, part I. Public Manager, 39(2), 17. Retrieved from http://ncampuscompact.org/files/ part1.pdf.

Lambright, K. (2008). Lessons outside of the classroom: Examining the effectiveness of service-learning projects at achieving learning objectives. Journal of Public Affairs Education, 14(2), 205-217.

Lambright, K. T., \& Lu, Y. (2009). What impacts the learning in service learning? An examination of project structure and student characteristics. Journal of Public Affairs Education, 15(4), 425-444.

Lewis, P. H., Lewis, A. N., \& Williams, F. D. (2012). Cultural competency in public administration programs. In K. Norman-Major \& S. Gooden (Eds.), Cultural competency for public administration (pp. 244-264). Armonk, NY: M.E. Sharpe.

Littlepage, L., Gazley, B., \& Bennet, T. A. (2012). Service-learning from the supply side. Nonprofit Management and Leadership, 22(3), 305-320.

Longo, N. V., \& Saltmarsh, J. (2011). New lines of inquiry in reframing international service learning into global service learning. In R. G. Bringle \& S. G. Jones (Eds.), International service learning: Conceptual frameworks and research (pp. 69-28). Sterling, VA: Stylus.

Metcalf, L. E. (2010). Creating international community service learning experiences in a capstone marketingprojects course. Journal of Marketing Education, 32(2), 155-171. doi:10.1177/0273475309360157.
Moore McBride, A., Brav, J., Menon, N., \& Sherraden, M. (2006). Limitations of civic space. Community Development Journal, 41(3), 307-320.

Moore McBride, A., Lough, B., \& Sherraden, M. (2012). International service and the perceived impacts on volunteers. Nonprofit \& Voluntary Sector Quarterly, 41(6), 969-990.

Murphy, J. P., \& Meyer, V. (2012). Going global: Strategies for study abroad at the School of Public Service, DePaul University, Chicago. Nonprofit Management and Leadership, 23(1), 137-151.

Network of Schools of Public Policy, Affairs, and Administration (NASPAA), Commission on Peer Review and Accreditation. (2014). Accreditation standards for master's degree programs. Retrieved from https://naspaaaccreditation.files.wordpress.com/ 2015/02/naspaa-accreditation-standards.pdf.

Norman-Major, K. (2011). Balancing the four E's: Or can we achieve equity for social equity in public administration? Journal of Public Affairs Education, 17(2), 233-252.

Norman-Major, K., \& Gooden, S. (Eds.). (2012). Cultural competency for public administration. Armonk, NY: M.E. Sharpe.

Pechak, C. M., \& Thompson, M. (2009). A conceptual model of optimal international service-learning and its application to global health initiatives in rehabilitation. Physical Therapy, 89(11), 11921204. doi:10.2522/ptj.20080378.

Perold, H., Graham, L. A., Mavungu, E. M., Cronin, K., Muchemwa, L., \& Lough, B. J. (2013). The colonial legacy of international voluntary service. Community Development Journal, 48(2), 179-196.

Phillips, A. (2011). Service-learning and social work competency-based education: A "goodness of fit"? Advances in Social Work, 12(1), 1-20.

Plater, W. M., Jones, S. G., Bringle, R. G., \& Clayton, P. H. (2009). Educating globally competent citizens through international service learning. In Ross Lewin (Ed.), The handbook on practice and research in study abroad (pp. 485-505). New York, NY: Routledge.

Pless, N. M., Maak, T., \& Stauhl, G. K. (2011) Developing responsible global leaders through international service-learning programs: The Ulysses experience. Academy of Management Learning \& Education, 10(2), 237-260. doi:10.5465/AMLE. 2011.62798932 . 
Rice, M. F. (2007). Promoting cultural competency in public administration and public service delivery: Utilizing self-assessment tools and performance measures. Journal of Public Affairs Education, 13(1), 41-57.

Rice, M. F., \& Matthews, A. L. (2012). A new kind of public service professional: Possessing cultural competency awareness, knowledge and skills. In K. Norman-Major \& S. Gooden (Eds.), Cultural competency for public administration (pp. 19-31). Armonk, NY: M.E. Sharpe.

Romack, J. (2003). Is service learning making the grade? Academic Exchange Quarterly, 7(2), 126-129.

Rubaii, N., \& Calarusse, C. (2012). The evolution of cultural competency as a standard for accreditation: The past, present, and future role of NASPAA accreditation. In K. Norman-Major \& S. Gooden (Eds.), Cultural competency for public administration (pp. 219-243). Armonk, NY: M.E. Sharpe.

Rubaii, N., Appe, S., \& Stamp, K. (2015). Are we getting them out of the country? The state of study abroad opportunities within NASPAA member programs. Journal of Public Affairs Education, 21(2), 179-198.

Ryan, S. W. (2010). Let's get them out of the country! Reflecting on the value of international immersion experiences for MPA students. Journal of Public Affairs Education, 16(2), 307-312.

Schroeder, K., Wood, C., Galiardi, S., \& Koehn, J. (2009). First, do no harm: Ideas for mitigating negative community impacts of short-term study abroad. Journal of Geography, 108(3), 141-147.

Stout, M. (2013). Delivering an MPA emphasis in local governance and community development through service learning and action research. Journal of Public Affairs Education, 19(2), 217-238.

Thomson, A. M., Smith-Tolken, A. R., Naidoo, A. V., \& Bringle, R. G. (2011). Service-learning and community engagement: A comparison of three national contexts. Voluntas, 22(2), 214. doi:10.1007/s11266-010-9133-9.

Tonkin, H. (2011). A research agenda for international service learning. In R. G. Bringle \& J. A. Hatcher, \& S. G. Jones (Eds), International service learning: Conceptual frameworks and research (pp. 191-224). Sterling, VA: Stylus.
Vail, P. (Director/Producer). (2013). Gringo trails [Documentary film]. Brooklyn, NY: Icarus Films.

White, S. (2004). Multicultural MPA curriculum: Are we preparing culturally competent public administrators? Journal of Public Affairs Education, 10(2), 111-123.

Wodicka, R., Swartz, N., \& Peaslee, L. (2012). Taking the classroom to Town Hall. Journal of Public Affairs Education, 18(2), 271-294.

Wyatt-Nichol, H., Brown, S. A., \& Haynes, W. E. (2011). Social class and socioeconomic status: Relevance and inclusion in MPA/MPP programs. Journal of Public Affairs Education, 17(2), 187-208.

Zemach-Bersin, T. (2008, March 7). American students abroad can't be "global citizens'. The Chronicle of Higher Education. Retrieved from http://chronicle.com/article/American-StudentsAbroad-Cant/25527.

\section{ABOUT THE AUTHORS}

Susan Appe is assistant professor of public administration at the College of Community and Public Affairs at Binghamton University, State University of New York. Her research centers on government-nonprofit relations, the evolution of the nonprofit sector in developed and developing countries, and the implications of international service learning in public affairs education.

Nadia Rubaii is associate professor of public administration in the College of Community and Public Affairs at Binghamton University, State University of New York. Her research examines issues of diversity with an emphasis on enhancing cultural competence in professional public service. Her research also examines the challenges of applying U.S.-based standards of educational quality in a comparative context, with a particular focus on Latin America. 
Kerry Stamp is associate director for study abroad in the Office of International Programs at Binghamton University, State University of New York, where she is also a doctoral student of public affairs. Her research areas of interest include diversity and inclusion in study abroad, and global service learning. 


\section{APPENDIX A: SURVEY INSTRUMENT}

Dear NASPAA Member Program Liaison:

The following short (7-question) survey regarding international opportunities for students in NASPAA member programs should take less than 2 minutes to complete. We appreciate your time and participation.

1. Which of the following degree programs does your department/college/school offer? (Check all that apply.)

Master's of Public Administration

Master's of Public Policy

Master's of Public Affairs

PhD or DPA (in Public Administration, Public Policy, or Public Affairs)

BA or BS (in Public Administration, Public Policy, Public Affairs)

Other

\section{NOTE}

For the remaining questions, please focus only on the master's level degree programs in public affairs (MPA, MPP, MPAff or related degree). These will be referred to simply as "MPA/MPP programs" but should be understood to include other master's programs encompassed by NASPAA's scope.

2. Is your MPA/MPP program NASPAA-accredited? $\quad \square$ Yes $\quad \square$ No

3. Where, if at all, do the terms "international," "global," or "world" (including variations on those terms) appear in your mission statement?

In the mission of the college/school/department and the MPA/MPP program

In the mission of the college/school/department only

$\square$ In the mission of the MPA/MPP program only

Not at all

Not sure

We do not have a mission statement 
4. Which of the following statements best reflects the message conveyed to MPA/MPP students about study abroad?

It is a mandatory component of the program

It is a recommended aspect of the program for all students

It is a recommended aspect of the program for some students, depending on their interests

It is an option for students

It is not an option for students at the present time but the program is considering developing options [skip to end and THANK YOU]

It is not an option for students and we have no plans to develop options [skip to end and THANK YOU]

For the purposes of the following questions, please consider any study abroad opportunities which are administered entirely or in part at the level of the MPA/MPP program; that is, where MPA/MPP faculty or staff oversee the program design, establish program requirements, evaluate student progress, or have similar levels of influence, even if other aspects of the study abroad program are administered by a central office outside the MPA/MPP program.

5. Which of the following statements apply? (Check all that apply.)

The MPA/MPP program offers full-semester or full-year study abroad programs

The MPA/MPP program offers short-term (less than a semester) study abroad programs

MPA/MPP study abroad programs are available only to MPA/MPP students

MPA/MPP study abroad programs are open to graduate students in other majors

MPA/MPP study abroad programs are open to undergraduate students as well

The MPA/MPP program does not offer any study abroad programs in-house

[skip to end and THANK YOU]

6. Do any of your MPA/MPP study abroad opportunities integrate international service learning?

Yes $\quad \square$ No $\quad \square$ Not sure

7. Please provide the name(s) and email contact information of faculty/staff who lead the study abroad program(s) in your department. 


\section{APPENDIX B: INTERVIEW PROTOCOL}

Confirm basic information from the survey regarding degrees offered, accreditation status, program and school mission, and study abroad.

According to the survey responses, your program is [required, encouraged, optional] and is available to [student types], and you have programs of [length]. Is that correct?

1. How many international programs do you have? In what countries are they located? For each program, can you tell me a little bit about how and when it started?

2. Using the following definition of international service learning, how many of those have a service learning component? For our purposes, service learning is a type of experiential learning that engages students in volunteer activities within a community as an integrated aspect of a course. In contrast to practice-based education (such as internships or fieldwork), where students are developing professional skills, servicelearning classes involve students in volunteer activities that are linked to specific learning objectives of the course. International service learning is an organized excursion taken by students in which students volunteer with local organizations to service the community where they are staying, engage in a cultural exchange, and learn about a daily reality very different from their own. International service learning involves intentional and continuous reflection before, during, and after the service experience.

3. Please describe the basic program characteristics for each of the study abroad programs you offer.

4. Can you explain the relationship and roles of you, other faculty or staff in your public affairs program, and a central university office for international programs?

5. Does the institution or program collect data on student participant characteristics (age, race, gender, first-generation students, etc.)? Has anyone analyzed it?
6. How do you define and measure program effectiveness or success?

Skip to question 11 for programs without international service learning (ISL). For those that have ISL, continue with these questions:

7. To what extent are the service partners and service projects consistent each time, or do they vary? What was done to develop and maintain the service partner relationships? Please provide two or three examples of the types of service projects your students have engaged in as part of this program.

8. Do you have any formal relationship with a university in that country as part of this program? If so, what is their role and how did you identify that partner? Do you have a reciprocal relationship to provide international service learning opportunities for students from that university or from another university?

9. There is considerable literature on the ethical challenges associated with international service learning. To what extent and in what ways are these issues addressed by the program before, during, and/or after the study abroad experience?

10. Based on your experience with this program, what lessons have you learned about international service learning and what advice would you offer to others?

11. Based on your experience with study abroad program(s), what lessons have you learned and what advice would you offer to others? 